\title{
sciendo
}

\section{EFFECT OF PRODUCTION SYSTEM AND AGE ON THE GROWTH PERFORMANCE AND CARCASS TRAITS OF PHEASANTS (PHASIANUS COLCHICUS)}

\author{
Umut Sami Yamak ${ }^{1}$, Musa Sarica ${ }^{1}$, Mehmet Akif Boz $^{2 \star}$, Ahmet Ucar ${ }^{3}$ \\ ${ }^{1}$ Department of Animal Science, Agricultural Faculty, Ondokuz Mayis University, Samsun, \\ 55139, Turkey \\ ${ }^{2}$ Department of Animal Science, Agricultural Faculty, Bozok University, Yozgat, 66100, Turkey \\ ${ }^{3}$ Department of Animal Science, Agricultural Faculty, Ankara University, Ankara, 06110, Turkey \\ •Corresponding author: m.akif.boz@bozok.edu.tr
}

\begin{abstract}
A total of 211 pheasants (Phasianus colchicus) were reared using two different production systems (free range and intensive) to determine the effect of production system and slaughter age on growth performance and carcass traits. Birds were slaughtered at 14, 16, and 18 weeks of age. Production system did not significantly affect body weight until 18 weeks; at this age, pheasants reared in free range exhibited a higher average weight (1149 $\mathrm{g}$ vs. $1012 \mathrm{~g})$. Total feed consumption and feed conversion ratios did not differ among production systems. The most in-demand portions of the carcass (breast and leg) were not affected by differences in production system. The leg and breast proportions which were the most edible parts of the carcass were around $26 \%$ and $35 \%$, respectively, in both free-range and intensive systems.
\end{abstract}

Key words: carcass, feed conversion ratio, free range, pheasant, production system

Pheasants are large birds that are commonly found in fields and on the edges of woodlands, particularly in the northern hemisphere. They belong to the Phasianidae family and have different varieties varying in colour, including brown, black, tan, yellow, orange, red, and green. Pheasants have an attractive appearance, making them popular animals kept for hobby purposes. Moreover, they are game birds most often consumed as a result of hunting (Kuzniacka and Adamski, 2010). For hunting purposes, they are kept in intensive conditions to supply stock for special hunting areas and nature reserves (Tucak et al., 2004; Yamak, 2015). However, rearing pheasants in intensive conditions has started to increase in proportion to the ever-increasing demand for pheasant meat in niche markets. Consumers prefer wild animals' meat for dietary reasons because they feed on native vegetation (Nuernberg 
et al., 2011). Also, they can easily adapt to habitats modified by humans (Franco and Lorenzo, 2013).

Most studies on pheasant meat production have been conducted on hunted birds (Hofbauer et al., 2010) or in confined conditions (Abrar et al., 2017; Strakova et al., 2005). Limited studies have investigated the growth traits of pheasants reared in extensive conditions (Franco and Lorenzo, 2013; Kokoszynski et al., 2011; Ricard et al., 2004). There is currently a lack of studies investigating the growth traits of pheasants reared in both completely confined and in semi-intensive conditions. Therefore, this study aims to investigate the growth and carcass traits of common pheasants (Phasianus colchicus) in free-range and intensive conditions at different slaughter ages.

\section{Material and methods}

The experiment was conducted between May and August 2015 at the Ondokuz Mayis University Agricultural Faculty's Research Farm, Turkey. All procedures were approved by the Ondokuz Mayis University Ethical Committee for Experimental Animals. Pheasant (Phasianus colchicus) eggs were collected from a flock reared at the Turkish Ministry of Forests and Water Affairs' Samsun Breeding Station. All eggs were collected and transferred to the farm's hatchery on the same day. Following a 25-day incubation period, 200 day-old chicks were randomly selected for use in the experiment.

Chicks were randomly allocated to pens belonging to either an intensive or freerange access production system that interspersed within windowed houses, with 4 pens per system and 25 to 27 chicks per pen. Pens $(3.5 \times 3.5 \mathrm{~m})$ were separated and covered by $0.5 \times 0.5 \mathrm{~cm}$ wire mesh to prevent birds from flying between pens. Each pen contained 1 round feeder and 1 round drinker. The intensive pen also contained an $8 \mathrm{~cm}$ layer of wood shavings used as litter, and no fresh litter was added during the production period. Heating was provided by infrared heaters, and economic white bulbs were used for lighting. A $24 \mathrm{~h}$ /day light regime was applied during the first 3 days. Light was incrementally decreased to $20 \mathrm{~h}$ /day over days 3 to 14, and then remained constant until 6 weeks, after which natural lighting (approximately $14 \mathrm{~h}$ /day) was applied until slaughter. After 6 weeks of age, birds in the free-range system were provided 24-hour access to free-range pens measuring $14 \times 3.5 \mathrm{~m}$ through a single doorway measuring $50 \times 90 \mathrm{~cm}$.

All birds were fed ad libitum using the same commercial layer chicken diet based on corn and soybean meal (190 g CP and 11.72 MJ ME, $10.0 \mathrm{~g}$ lysine, $4.00 \mathrm{~g}$ methionine, $11.0 \mathrm{~g} \mathrm{Ca}, 6.00 \mathrm{~g} \mathrm{P}$ per $\mathrm{kg}$ ) until 12 weeks of age, and with layer chicken developer diet (160 g CP, 11.30 MJ ME, $3.50 \mathrm{~g}$ methionine, $7.20 \mathrm{~g}$ lysine, $10.0 \mathrm{~g}$ $\mathrm{Ca}, 4.00 \mathrm{~g}$ P per $\mathrm{kg}$ ) from 12 weeks until the end of the experiment. Water was also provided ad libitum.

All birds were wing-banded and individually weighed (precision electronic scales, TEM TPG, İstanbul, Turkey) at hatching, 2, 4, 6, 8, 10, 12, 14, 16, and 18 
weeks of age. Cumulative feed consumption, feed conversion ratios, and mortality were evaluated for each replicate.

Carcass traits were evaluated by randomly selecting and slaughtering four (two male and two female) pheasants per replication at 14, 16, and 18 weeks ( 16 birds per age for a total of 48 birds for each production system; 96 birds in total). An 8-hour fasting period was applied before slaughter. All birds were weighed prior to slaughter and after blood flow at slaughter, and the amount of blood was calculated and recorded as the ratio to body weight. Birds were slaughtered in a semi-automated slaughtering house. Scalding $\left(1 \mathrm{~min}\right.$ at $\left.56^{\circ} \mathrm{C}\right)$, plucking, cold-water chilling, vent opening, evisceration, and air chilling were performed using the slaughter lines. Carcasses were weighed after these operations and the ratio to body weight was used as hot dressing percentage. Carcasses were weighed again after stored 24 hours at $+4^{\circ} \mathrm{C}$ and the ratio to body weight was used as cold dressing percentage. Feather amounts were calculated by weighing carcasses after plucking and recorded as the ratio to body weight. Abdominal fat was measured by weighing the fat surrounding abdominal muscles, cloaca, and inner organs after carcasses were chilled. Carcasses were cut into parts according to standard methods, and leg (thigh and drumstick), breast, wing, back, neck, and total edible inner organ (heart, liver and gizzard) weights were recorded as percentages of cold-carcass weights (Sarica et al., 2011).

Statistical analysis was performed using SPSS software (Version 16). Analysis of variance with a factorial arrangement (production system and age) was used to test the effects of production system, age and interaction for the feed consumption, feed conversion ratios and body weight measurement (for first 6 weeks). Production system, age and gender interactions were used for all slaughter and carcass traits and body weight after 8 weeks of age. Data was subjected to arc-sine transformation. Duncan's multiple range test was used to compare means. A level of $\mathrm{P}<0.05$ was considered statistically significant.

\section{Results}

Pheasants were not permitted to access free-range conditions until 6 weeks. Therefore, growth traits were evaluated for two different periods (0-6 weeks and 6-18 weeks). Body weights, cumulative feed consumption per bird, feed conversion ratios (FCR), and mortality for the first 6 weeks are provided in Table 1, while the effects of production system and gender on body weight at different ages are provided in Table 2.

No significant differences were observed between the body weights of pheasants reared in intensive or free-range conditions until 16 weeks of age. However, the difference between the two groups was significant at 18 weeks $(\mathrm{P}<0.01)$. Males had higher weights than females at all ages $(\mathrm{P}<0.01)$. Cumulative feed consumption, FCR, and mortality for both production systems at different ages are provided in Table 3. Slaughter age had significant effects on feed consumption, FCR and mortality. Differences in feed consumption, FCR, and mortality between production systems were not significant. 
Table 1. Pheasant body weight, cumulative feed consumption and mortality between 0 and 6 weeks

\begin{tabular}{l|c|c|c|c|c|c|c}
\hline $\begin{array}{c}\text { Age } \\
\text { (weeks) }\end{array}$ & $\mathrm{N}$ & $\begin{array}{c}\text { Body } \\
\text { weight (g) } \\
\mathrm{x} \pm \mathrm{Sx}\end{array}$ & Max. & Min. & $\begin{array}{c}\text { Feed } \\
\text { consumption } \\
(\mathrm{g} / \mathrm{bird})\end{array}$ & $\begin{array}{c}\text { FCR } \\
\text { (g feed/g } \\
\text { body weight) }\end{array}$ & $\begin{array}{c}\text { Mortality } \\
(\%)\end{array}$ \\
\hline Hatch & 211 & $21.2 \pm 0.13$ & 27.3 & 15.9 & - & - & - \\
2 & 209 & $61.1 \pm 0.91$ & 106.1 & 24.9 & 174.4 & 2.85 & 0.94 \\
4 & 208 & $141.9 \pm 1.94$ & 245.5 & 76.0 & 417.4 & 2.94 & 1.42 \\
6 & 201 & $293.8 \pm 4.94$ & 479.8 & 140.0 & 825.7 & 2.81 & 4.73 \\
\hline
\end{tabular}

Table 2. Effect of production system on body weight changes of pheasants at different ages

\begin{tabular}{|c|c|c|c|c|c|c|c|}
\hline \multirow{2}{*}{$\begin{array}{l}\text { Production } \\
\text { system }\end{array}$} & \multirow{2}{*}{ Gender } & \multicolumn{6}{|c|}{ Body weight (g/week) } \\
\hline & & 8 & 10 & 12 & 14 & 16 & 18 \\
\hline \multirow[t]{2}{*}{ Free-range } & M & 402.7 & 561.5 & 748.6 & 952.4 & 1087.5 & 1218.4 \\
\hline & $\mathrm{F}$ & 346.9 & 491.8 & 636.3 & 805.8 & 910.7 & 1079.7 \\
\hline \multirow[t]{2}{*}{ Intensive } & M & 407.8 & 573.5 & 777.0 & 959.0 & 1100.2 & 1156.1 \\
\hline & $\mathrm{F}$ & 343.8 & 480.1 & 631.9 & 748.5 & 841.1 & 867.3 \\
\hline \multicolumn{2}{|l|}{ SEM } & 5.0 & 6.8 & 8.5 & 8.3 & 10.2 & 18.3 \\
\hline \multicolumn{8}{|c|}{ Effects } \\
\hline \multicolumn{2}{|c|}{ Production system } & NS & NS & NS & NS & NS & ** \\
\hline & free-range & 374.8 & 526.6 & 704.5 & 879.1 & 999.1 & 1149.1 \\
\hline & intensive & 375.8 & 526.7 & 692.9 & 853.2 & 970.7 & 1011.7 \\
\hline \multirow[t]{3}{*}{ Gender } & & $* *$ & $* *$ & $* *$ & $* *$ & $* *$ & ** \\
\hline & male & 405.3 & 567.5 & 763.3 & 955.2 & 1093.9 & 1187.2 \\
\hline & female & 345.3 & 485.9 & 634.1 & 777.1 & 875.9 & 973.5 \\
\hline \multicolumn{2}{|c|}{$\begin{array}{l}\text { Production system } \times \\
\text { Gender }\end{array}$} & NS & NS & NS & NS & NS & $* *$ \\
\hline
\end{tabular}

**P $<0.01$, SEM: Standard error of means, NS: Insignificant, M: Male, F: Female.

Slaughter traits for pheasants are provided in Table 4. Feather amount, carcass yield, and abdominal fat ratios were the only traits significantly affected by production system. Dressing percentage was significantly affected by production system and slaughter age. Birds reared in the intensive system had higher dressing percentages. Feather amount was better in the free-range system $(\mathrm{P}<0.05)$. On the other hand, highest dressing percentage was achieved at 16 weeks $(\mathrm{P}<0.05)$. Abdominal fat ratios were highest in terms of carcass weight in free-range systems $(\mathrm{P}<0.05)$. Flowed blood ratio and feather amount were not significantly affected by slaughter age. Males had a significantly higher body weight, head, and feet weights, whereas females had higher level of abdominal fat $(\mathrm{P}<0.01)$. 
Table 3. Pheasant feed consumption, FCR and mortality at different ages

\begin{tabular}{|c|c|c|c|c|}
\hline $\begin{array}{c}\text { Production } \\
\text { system }\end{array}$ & $\begin{array}{c}\text { Age } \\
\text { (weeks) }\end{array}$ & $\begin{array}{l}\text { Feed consumption } \\
(\mathrm{g} / \mathrm{bird})\end{array}$ & $\begin{array}{c}\text { FCR } \\
(\mathrm{g} \mathrm{feed} / \mathrm{g} \mathrm{BW})\end{array}$ & $\begin{array}{c}\text { Mortality } \\
(\%)\end{array}$ \\
\hline \multirow[t]{6}{*}{ FR } & 8 & 1461.9 & 3.91 & 1.0 \\
\hline & 10 & 1875.4 & 3.55 & 1.0 \\
\hline & 12 & 2339.0 & 3.37 & 1.2 \\
\hline & 14 & 2740.4 & 3.12 & 1.2 \\
\hline & 16 & 3470.5 & 3.50 & 1.4 \\
\hline & 18 & 4283.0 & 3.70 & 1.5 \\
\hline \multirow[t]{7}{*}{ Int } & 8 & 1475.9 & 3.93 & 1.2 \\
\hline & 10 & 1894.3 & 3.61 & 1.4 \\
\hline & 12 & 2239.7 & 3.19 & 1.5 \\
\hline & 14 & 2684.8 & 3.15 & 1.5 \\
\hline & 16 & 3504.3 & 3.61 & 1.5 \\
\hline & 18 & 3842.5 & 3.80 & 1.7 \\
\hline & \multicolumn{4}{|c|}{ Effects } \\
\hline \multicolumn{2}{|c|}{ Production system } & NS & NS & NS \\
\hline \multicolumn{2}{|l|}{ Age } & $* *$ & $* *$ & $*$ \\
\hline \multicolumn{2}{|c|}{$\begin{array}{l}\text { Production system } \\
\times \text { Age }\end{array}$} & NS & NS & NS \\
\hline
\end{tabular}

$* \mathrm{P}<0.05 ; * * \mathrm{P}<0.01, \mathrm{SEM}$ : standard error of means, NS: insignificant; FR: free-range, Int: intensive, FCR: feed conversion ratio, BW: body weight.

Carcass part weights and ratios are provided in Table 5. The intensive system was better for carcass part weights and ratios, while the intensive and free-range systems were comparable with each other. Back, wing, and neck ratios were higher in intensive systems. Excluding the back ratio, all carcass part weights and ratios were affected by slaughter age $(\mathrm{P}<0.01)$. Also, females had higher breast ratios than males $(\mathrm{P}<0.01)$. Interactions among slaughter age and gender that not included breast weight were determined as insignificant.

\section{Discussion}

Mean chick weight was $21.24 \mathrm{~g}$ at hatch. This is in line with the findings of Ipek and Yilmaz Dikmen (2007), who observed a weight of $21.8 \mathrm{~g}$ at hatch. Similarly, Strakova et al. (2005) reported a $20.0 \mathrm{~g}$ weight at hatch. Pheasants were reared intensively until 6 weeks of age, reaching 293.78 g mean body weight by this age. Previous studies observed the body weights of pheasants at this age to be approximately 350 g (Kokoszynski et al., 2011; Strakova et al., 2005). These differences could be related to bird variety and feed. 


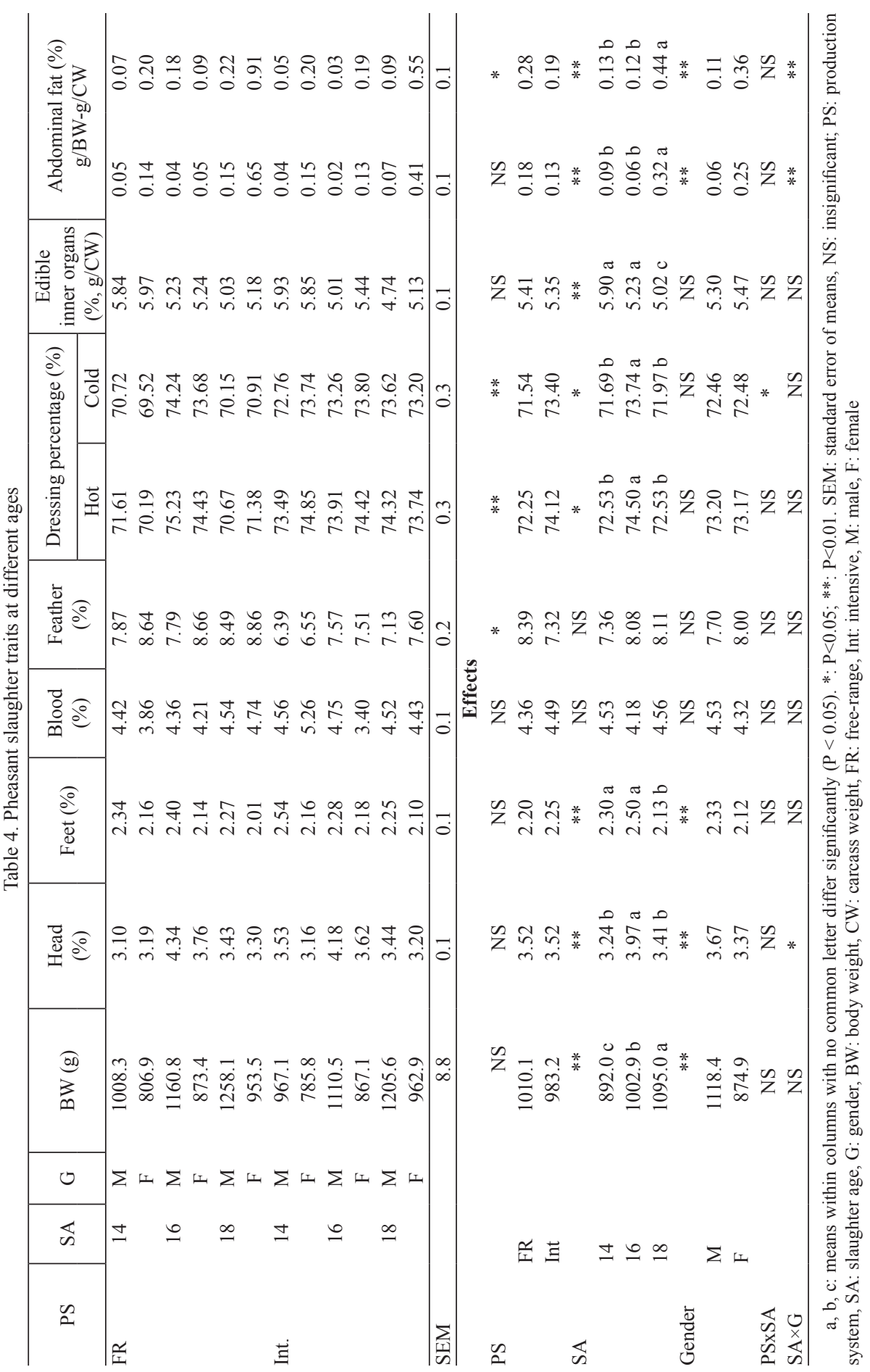




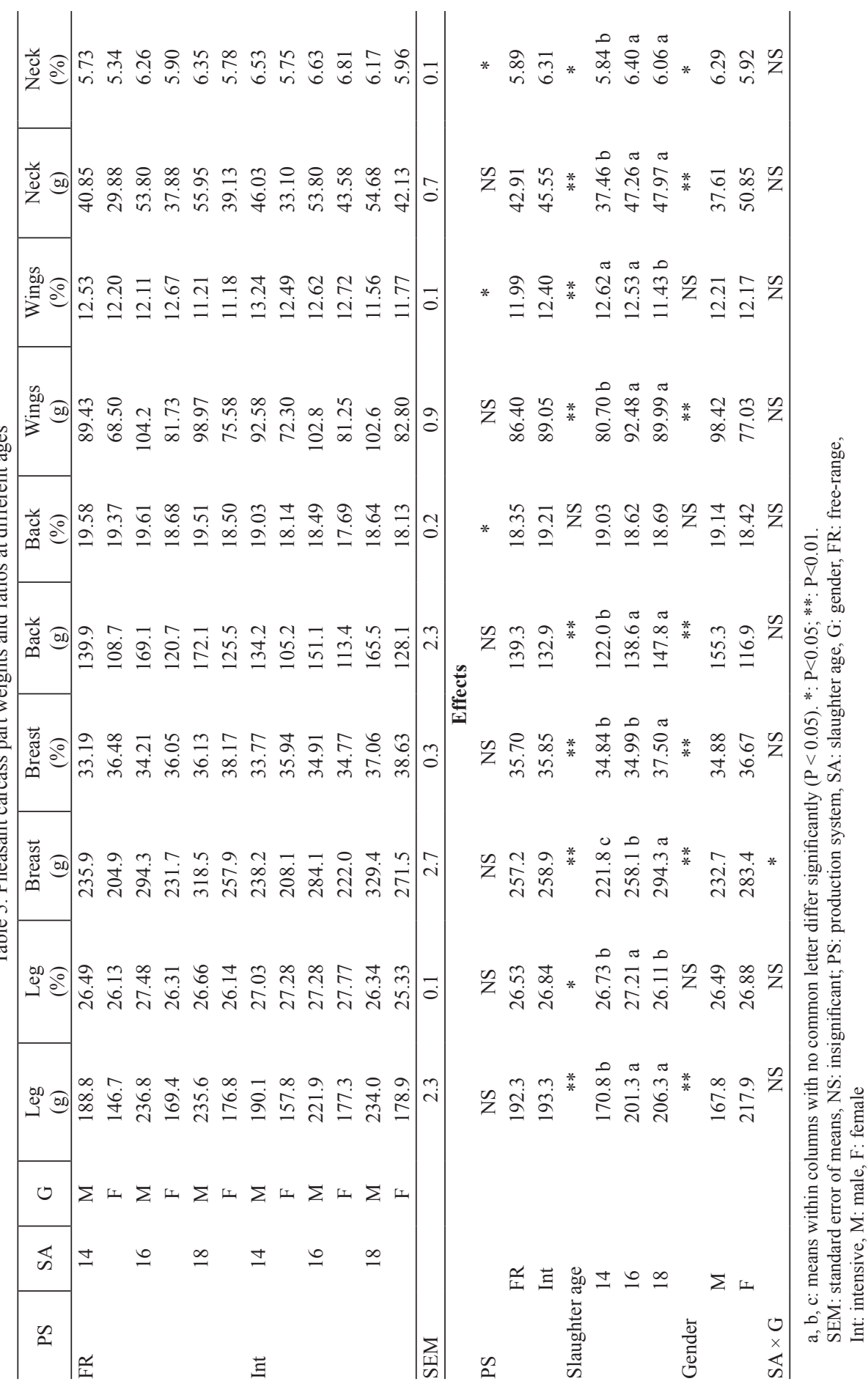


Birds in the free-range group had access to free-range conditions after 6 weeks of age. After the experimental group had access to free-range conditions for two weeks, body weights of birds in both groups were nearly the same. Free-range birds exhibited higher body weights between 12 and 16 weeks of age, though these differences were not statistically significant. When the pheasants reached 18 weeks of age, birds reared in the free-range group were significantly heavier than the intensive group. Previous studies have highlighted that in most poultry species including turkey (Kaiser et al., 2012), goose (El-Hanoun et al., 2012), duck (El-Edel et al., 2015), partridge (Yamak et al., 2016), guinea fowl (Yamak et al., 2018), and chicken (Ipek and Sozcu, 2017), intensive birds exhibit higher body weights than free-range birds. In this regard, pheasants are different from these poultry species because they were not domesticated for commercial production. In free-range conditions, birds had more space for physical conditioning, social interaction, and were exposed to natural weather conditions. Therefore, improved living conditions for free-range birds could have resulted in higher body weights. Previously reported body weight values for pheasant are in line with our findings. Most of these studies completed the rearing period at 16 weeks and observed weights of 1017-1239 $\mathrm{g}$ for males and 741-956 $\mathrm{g}$ for females (Ipek and Yilmaz Dikmen, 2007; Kokoszynski et al., 2011). Therefore, according to the results of these studies, weights over $1 \mathrm{~kg}$ could be considered an acceptable marketing weight for pheasants.

Feed consumption and feed conversion ratio are the most important traits for producers in commercial production. Pheasants in both systems consumed similar amount of feed over the production period. No significant differences were observed between feed consumption and feed conversion ratios. Sarica et al. (1999) observed that pheasants consumed approximately $5 \mathrm{~kg}$ of feed in 15 weeks, with an FCR of 5.14 at this age. Similarly, Ipek and Yilmaz Dikmen (2007) reported that total feed consumption for pheasants was between 4200 and $5080 \mathrm{~g}$ at 16 weeks. They also determined that FCR was between 5.1 and 5.4. According to Blake and Hess (2009), cumulative feed consumption / FCR for ring-necked pheasant was $4936 \mathrm{~g} / 4$ and $6082 \mathrm{~g} / 4.77$ at 16 and 18 weeks, respectively. Kokoszynski et al. (2018) reported the FCR to be 4.96 at 16 weeks. Total feed consumption and FCR values obtained in the present study at 16 and 18 weeks (3.47-4.28 $\mathrm{kg}$ and $3.50-3.80$, respectively) were lower than reported values. Mortality was not affected by production system and was approximately $1.5 \%$ in the rearing period. Previously reported mortalities for pheasants were higher than our findings. Sarica et al. (1999) observed mortality of $10.4 \%$ at 15 weeks, whereas Ipek and Yilmaz Dikmen (2007) observed mortality of $5 \%-8.33 \%$ at 16 weeks. Mortality is mostly affected by management during rearing. Pheasants are fearful birds and anything that disturbs them could be the reason for struggling in the house and this could cause deaths. The poultry house of our study was located in an isolated part of the farm. All factors which could be the factor for disturbing the birds were minimized in the study. On the other hand, quality of the feed and water and other disinfection rules were optimized in the study. It is thought that all these management factors caused lower mortality in the study.

Production system, slaughter age, and gender did not have any significant effect on the flowed blood ratios of slaughtered pheasants. However, our results (between 
$4.18 \%$ and $4.53 \%$ ) were higher than the findings of Kokoszynski et al. (2011), who observed a blood ratio in pheasants to range between $1.9 \%$ and $2.4 \%$ of body weight at different ages. This difference could be related to the slaughtering process. Bleeding could change according to slaughtering method (Thaxton et al., 2009), and losing $4-5 \%$ of body weight in bleeding is normal (Barbut, 2015). Pheasant feather to body weight ratio was not affected by gender or slaughter age. Conversely, it was affected by production system. Pheasants reared in free-range protected their feathers better than intensive pheasants ( $8.39 \%$ vs. $7.32 \%$, respectively). It was shown that production system could play a factor in the protection of feathers, which is related to stress factors in intensive systems; therefore, birds could experience improved plumage condition in free-range systems (Boz et al., 2017; Yamak et al., 2018). Head and shanks are the non-edible components of the body of pheasants. In a previous study, the ratios of head and shanks to body weight were reported to be approximately $3.5 \%$ and $2.4 \%$, respectively (Kokoszynski et al., 2011). Our findings are congruent with these reported values, and production system did not affect these ratios. Contrary to the results of Kokoszynski et al. (2011), who did not find difference between the head and shank ratios of female and male pheasants, we observed males exhibiting higher ratios.

The differences between dressing percentages of free-range and intensive pheasants were significant. Differences between hot and cold dressing percentages could be related to water in the carcasses due to plucking, given that hot dressing percentages were calculated using carcass weight immediately following slaughter, whereas cold dressing percentages were calculated using carcass weight after chilling, when the additional water would have been removed. However, dressing percentages did not differ between male and female birds. Kokoszynski et al. (2011) reported the dressing percentages of male pheasants $(70.8 \%)$ to be higher than in female pheasants $(69.7 \%)$. The average dressing percentages obtained in this study were higher than the 70.8\% reported by Severin et al. (2006), but similar to Sarica et al. (1999) and Kokoszynski et al. (2012), both of whom reported mean dressing percentages of pheasants of $72-75 \%$.

The edible inner organs (heart, liver, and gizzard) constitute 3-5\% of carcass weight in poultry species. In this study, the rate of edible organs was between $5.02 \%$ and $5.90 \%$. Neither production system nor gender affected the proportion of edible inner organs, but it was significantly decreased by slaughter age. Abdominal fat ratios were significantly affected by production system, with higher abdominal fat ratios in free-range pheasants when compared to intensive pheasants $(0.29 \%$ vs. $0.19 \%$, respectively). Abdominal fat significantly increased at 18 weeks of age, and females exhibited significantly higher ratios than males. The abdominal fat ratios of pheasants were generally found to be lower than $1 \%$ of carcass weight. Also, similar to our findings, it was reported that female pheasants had higher abdominal fat values than males (Kokoszynski et al., 2011; Sarica et al., 1999; Strakova et al., 2005).

Breast and leg muscles are the most in-demand portions of the poultry carcass; therefore, the ratio of breast to total body weight is an important factor for consumption. In modern chicken broilers, this ratio is over 35\% (Yamak et al., 2014). Similarly, Sarica et al. (1999) reported a pheasant breast ratio of 35-36\% for whole carcass. 
In our study, the breast ratio of pheasants was $34-37 \%$ of whole carcass. Breast ratio was not affected by production system, but gender and slaughter age affected this ratio. Females had a higher ratio than males, and the ratio increased at 18 weeks of age. These findings were higher than the results of Kokoszynski et al. (2011) and Franco and Lorenzo (2013), who observed breast ratios of 32\% and $28.77 \%$, respectively.

Moreover, no significant difference was observed between the leg ratios of intensive and free-range pheasants. Leg ratios in this study were lower than those reported by Sarica et al. (1999), and Franco and Lorenzo (2013), which were 28-31\% and $31 \%$, respectively. However, leg ratios in this study were higher than those observed by Kokoszynski et al. (2011) (24.5\%).

\section{Conclusion}

Pheasants are non-domesticated game birds whose meat is preferred in niche markets. Rearing these birds in intensive conditions has become popular to meet the demand. In particular, people prefer them for their "gamey" taste. Because pheasants are not domesticated birds, free-range production could be more suitable for pheasant rearing. The results of this study indicate that production system did not affect the total feed consumption and feed conversion ratios of pheasants. However, birds reared in free-range exhibited improved body weights at 18 weeks, though the differences were not significant at other slaughter ages. This could be related to improved living conditions for the free-range birds. Also, neither free-range nor intensive systems had any advantage with regard to the body components of carcass. According to the results, 16 weeks should be the most suitable age for slaughter. In conclusion, rearing pheasants in animal-friendly or organic production systems could have advantages for both consumers and producers.

\section{Acknowledgments}

Authors are thankful to Abalioglu Feed Mill Co. for their support.

\section{References}

A brar M., N a z S., A h mad Q.A., Mali k K., Tanveer A., S a ghe er A., Hus sa in S., Kau s a r G., T a b a s s u m S., A $1 \mathrm{taf}$ M., I q b a 1 M.A. (2017). Effect of temperature on growth and feed consumption rate of Korean ring necked pheasant (Phasianus colchicus). J. Entomol. Zool. Stud., 5: 103-106.

B arbut S. (2015). Stunning. In: The science of poultry and meat processing. Chapter 8. Canada, pp. $1-26$.

B 1 a k e P.J., H e s s J.B. (2009). Feeding Game Birds: Pheasant, Quail, and Partridge. Alabama Cooperative Extension System, ANR-1343, Alabama, USA.

B o z M.A., S a r 1 c a M., Yamak U.S. (2017). Effect of production system on foot pad dermatitis (FPD) and plumage quality of geese. Europ. Poult. Sci., 81.

E 1 - E d e 1 M.A., E 1 - K holy a S.Z., A b o u - I s mail U.A. (2015). The effects of housing systems on behaviour, productive performance and immune response to avian influenza vaccine in three breeds of ducks. Int. J Agric. Innov. Res., 3: 1496-1505.

E 1 - $\mathrm{H}$ a $\mathrm{n}$ o u n A.M., A t $\mathrm{i}$ a Y.A., G a d H.A.M., A b d e 11 a M.M. (2012). Effect of different managerial systems on productive and reproductive traits, blood plasma hormones and serum biochemical constituents of geese. Animal, 6: 1795-1802. 
Franco D., L or en zo J.M. (2013). Meat quality and nutritional composition of pheasants (Phasianus colchicus) reared in an extensive system. Brit. Poult. Sci., 54: 594-602.

H o fb a u e r P., S muld e r s F.J.M., Vodnan s k y M., P a u l s e n P., E 1 - G h a r e e b W.R. (2010). A note on meat quality traits of pheasant (Phasianus colchicus). Eur. J. Wildl. Res., 56: 809-813.

I p e k A., S o z c u A. (2017). The effects of access to pasture on growth performance, behavioural patterns, some blood parameters and carcass yield of a slow-growing broiler genotype. J. Appl. Anim. Res., 45: 464-469.

I pek A., Y i $1 \mathrm{maz}$ Dikmen B. (2007). The relationship between growth traits and egg weight in pheasants (P. colchicus). J. Biol. Environ. Sci., 1: 117-120.

Ka i s e r B., N a za m K., A s m a K., S u man R.M., Ty a gi A.K. (2012). Effect of intensive and semi-intensive rearing systems on overall performance of turkey. Indian J. Anim. Nutr., 29: 275-278.

Kokoszynski D., Bernacki Z., Cisowska A. (2011). Growth and development of young game pheasants (Phasianus colchicus). Arch. Tierzucht, 54: 83-92.

K o k o s z y n s k i D., B e r n a c k i Z., D u s z y n s k i L. (2012). Body conformation, carcass composition and physicochemical and sensory properties of meat from pheasants of different origin. Czech J. Anim. Sci., 57: 115-124.

Kokoszynski D., Kotowicz M., Piwczyński D., Bernacki Z., Podkówka Z., Dorszew ski P., Grabow ic z M., S a leh M. (2018). Effects of feeding whole-grain triticale and sex on carcass and meat characteristics of common pheasants. Italian J. Anim. Sci., 17: 1083-1093.

K u z n i a c ka J., A d a m s ki M. (2010). Growth rate of body weight and measurements in pheasants reared up to the 24th week of life. Arch. Tierzucht, 53: 360-367.

Nuernberg K., S lamecka J., Mojto J., Gasparik J., Nuernberg G. (2011). Muscle fat composition of pheasants (Phasianus colchicus), wild ducks (Anas platyrhynchos) and black coots (Fulica atra). Eur. J. Wildl. Res., 57: 795-803.

R ic ard F.H., P etitjean M.J., Melin J.M., Marche G., Malin e au G. (1991). Growth rate and abdominal fat of young pheasants reared in aviaries or in confinement (in French). INRA Prod. Anim., 4: 117-121.

S a r i c a M., K a r a c a y N., C a m c i O. (1999). Slaughter age and carcass traits of pheasants. Arch. Geflügelk., 63: 182-184.

S a r i c a M., O c a k N., Turh a n S., K o p C., Ya m a k U.S. (2011). Evaluation of meat quality from 3 turkey genotypes reared with or without free range access. Poultry Sci., 90: 1313-1323.

Severin K., Masek T., Janicki Z., Konjevic D., Slavica A., Hrupacki T. (2006). Copunisation of pheasants at different age. Vet. Arhiv., 76: 211-219.

S trak ova E., Vit u la F., S u ch y P., Ve cerek V. (2005). Growth intensity and carcass characteristics of fattened pheasant poults. Krmiva, 47: 73-82.

Thaxton J.P., Vizzier Thaxton Y., Schilling W., Christensen K., Stuckey R., Purs we 11 J.L., Branton S.L., White P. (2009). A new humane slaughter method for broilers - Low atmospheric pressure (LAPS). Proc. 8th European Symposium on Poultry Welfare, 18-22.05.2009, Cervia, Italy. Book abstracts, p. 42.

Tucak Z., Šk rivanko M., Krznarić M., P o s a vč ević S., B o škovićc I. (2004). Indicators of biological value of the pheasants meat originated from natural and controlled breeding. Acta Agric. Slov., Suppl., 1: 87-91.

Yamak U.S. (2015). Artificial breeding of wild birds in Turkey: Partridge breeding case. Indian J. Anim. Res., 49: 258-261.

Y a m a k U.S., S a r i c a M., B o z M.A. (2014). Comparing slow-growing chickens produced by twoand three-way crossings with commercial genotypes. 1. Growth and carcass traits. Europ. Poult. Sci., 78. DOI: 10.1399/eps.2014.29.

Yamak U.S., S aric a M., B oz M.A., U c ar A. (2016). The effect of production system (barn and free-range), slaughtering age and gender on some carcass traits and meat quality of partridges (A. chukar). Brit. Poultry Sci., 57: 185-192.

Y a m a k U.S., S a r i c a M., B o z M.A., U c a r A. (2018). Effect of production system (barn and freerange) and slaughter age on some production traits of guinea fowl. Poultry Sci., 97: 47-53. 